\title{
SYNTHESIS, CHARACTERIZATION, TOPOGRAPHICAL MODIFICATION, AND SURFACE PROPERTIES OF COPOLY(IMIDE SILOXANE)S
}

\author{
Christopher J. Wohl ${ }^{1, *}$, Brad M. Atkins ${ }^{2}$, Marcus A. Belcher ${ }^{3, \S}$, John W. Connell ${ }^{1}$ \\ ${ }^{1}$ NASA Langley Research Center, Hampton, VA 23681-2199 \\ ${ }^{2}$ Langley Aerospace Research Summer Scholar (LARSS), NASA Langley Research Center, \\ Hampton, VA 23681-2199 \\ ${ }^{3}$ National Institute of Aerospace, Hampton, VA 23666-6147
}

\begin{abstract}
Novel copoly(imide siloxane)s were synthesized from commercially available aminopropyl terminated siloxane oligomers, aromatic dianhydrides, and diamines. This synthetic approach produced copolymers with well-defined siloxane blocks linked with imide units in a random fashion. The copoly(amide acid)s were characterized by solution viscosity and subsequently used to cast thin films followed by thermal imidization in an inert atmosphere. Thin films were characterized using contact angle goniometry, attenuated total reflection Fourier transform infrared spectroscopy, confocal and optical microscopy, and tensile testing. Adhesion of micronsized particles was determined quantitatively using a sonication device. The polydimethylsiloxane (PDMS) moieties lowered the copolymer surface energy due to migration of siloxane moieties to the film's surface, resulting in a notable reduction in particle adhesion. A further reduction in particle adhesion was achieved by introducing topographical features on a scale of several to tens of microns by a laser ablation technique.
\end{abstract}

This paper is work of the U.S. Government and is not subject to copyright protection in the U.S.

* To whom correspondence should be addressed: christopher.j.wohl@nasa.gov, (757) 864-8074

$\S$ Currently employed at The Boeing Company: tony.belcher@boeing.com, (206) 544-6154 


\section{INTRODUCTION}

As part of a program to investigate polymeric materials with surfaces designed to have nominal particle adhesion forces, a series of copoly(imide siloxane)s with varying siloxane chain lengths were prepared and characterized. Copoly(imide siloxane)s were selected because of the unique combination of properties that these materials exhibit with specific attributes from each material family. Aromatic polyimides are known to have good properties for space applications such as radiation resistance, low moisture uptake, good electrical insulating properties, excellent thermal stability, and good mechanical properties.(Polyimides, 1990) Likewise, siloxanes are known to provide improved processability, increased impact resistance, decreased dielectric constants,(Mahoney et al., 2002) resistance to erosion by reactive oxygen species,(Fischer et al., 2010; Park et al., 2003; Tiwari et al., 2004) and of greatest significance for this work, a reduction

of the material's surface energy.(Park et al., 2003) The surface energy of a material, $\gamma$, plays a pivotal role in determining the material's wettability, adhesive behavior, magnitude of particulate adhesive interactions, and chemical resistance. In general, materials with high surface energies are more easily wetted by incident solvents, capable of greater adhesive bond strength with other substrates, and more likely to accumulate surface contaminants (both chemical contamination and debris).

This work is part of a larger NASA activity to develop strategies to minimize adhesion of lunar dust to a variety of surfaces envisioned for future applications on the lunar surface involving increasingly longer durations. Based on past experience, the lunar environment is known to pose major challenges to a sustained presence with lunar dust being a high priority concern requiring a variety of mitigation or minimization strategies.(Taylor et al., 2005) Lunar dust, defined as the fines portion with particulate diameters $\leq 50 \mu \mathrm{m}$, is highly abrasive, porous, chemically activated, electrostatically charged, and can be magnetic.(Abbas et al., 2007; Colwell et al., 2007; Halekas et al., 2007; Sternovsky et al., 2002; Taylor and Meek, 2005) Other lunar environmental issues that could negatively impact lunar surface missions include high vacuum, no humidity, low gravity, temperature fluctuation $\left(-150\right.$ to $\left.100{ }^{\circ} \mathrm{C}\right)$, triboelectrification, energetic particle bombardment, and ultraviolet radiation. Additionally, there is evidence that the lunar dust has a dynamic component with the greatest degree of mobility occurring at the terminator, the separation between day and night sides of the lunar surface, due to the dramatic change in 
electrostatic potential.(Borisov and Mall, 2006; Stubbs et al., 2006) With these properties, lunar dust presents a tremendous challenge for the successful completion of lunar missions, both manned and robotic. Further complicating this challenge is the lack of any correlation between measurable properties under terrestrial conditions and their behavior in the lunar environment.

As a passive approach (i.e., requiring no external energy) to mitigate lunar dust adhesion to surfaces, low surface energy copoly(imide siloxane)s with various siloxane segment lengths were prepared and characterized. Further reductions in surface energy were achieved by the introduction of topographical features on a scale of several to tens of microns via a laser ablation patterning technique.(Wohl et al., 2010a) This paper discusses the relationship between surface energies, as determined by contact angle goniometry, and quantitative adhesion forces, as measured by a custom adhesion force measurement device.(Wohl et al., 2011)

\section{EXPERIMENTATION}

\subsection{Materials}

Prior to use, 2,2-bis(3,4-dicarboxyphenyl)hexafluoropropane dianhydride (6FDA, Clariant Corporation, $\left.\mathrm{T}_{\mathrm{m}}=242^{\circ} \mathrm{C}\right)$ was vacuum dried and 3,4'-oxydianiline (3,4'-ODA, Aldrich, $\mathrm{T}_{\mathrm{m}}=71$ ${ }^{\circ} \mathrm{C}$ ) was vacuum distilled. 4,4'-Oxydiphthalic anhydride (ODPA, Chriskev Company, Inc., $\mathrm{T}_{\mathrm{m}}=$ $\left.226{ }^{\circ} \mathrm{C}\right), 4,4$ '-oxydianiline (4,4'-ODA, Wakayama Seika Kogya Co. Ltd, $\left.\mathrm{T}_{\mathrm{m}}=188{ }^{\circ} \mathrm{C}\right), 2,2$ bis[4-(4-aminophenoxy)phenyl]hexafluoropropane (4-BDAF, Wakayama Seika Kogya Co. Ltd, $\mathrm{T}_{\mathrm{m}}=162^{\circ} \mathrm{C}$ ), and aminopropyl terminated siloxanes (Gelest) were used as received. The number average molecular weight of the siloxane materials was determined using ${ }^{1} \mathrm{H}$ NMR spectroscopy. Differential scanning calorimetry (DSC) was conducted using a Setaram Instrumentation DSC 131 with a heating rate of $20^{\circ} \mathrm{C} / \mathrm{min}$ from -150 to $350{ }^{\circ} \mathrm{C}$ for determination of glass transition temperatures $\left(\mathrm{T}_{\mathrm{g}}\right)$ and $10{ }^{\circ} \mathrm{C} / \mathrm{min}$ from room temperature to $300{ }^{\circ} \mathrm{C}$ for determination of melting points $\left(\mathrm{T}_{\mathrm{m}}\right)$. Dynamic mechanical analysis (DMA) experiments were performed using a TA Instruments DMA Q800 with a heating rate of $1{ }^{\circ} \mathrm{C} / \mathrm{min}$ from -150 to $300{ }^{\circ} \mathrm{C}$ at $1 \mathrm{~Hz}$. Polymer film mechanical properties were determined on a Sintech $2 \mathrm{~W}$ load frame with a crosshead speed of $5.08 \mathrm{~mm} / \mathrm{min}$, ASTM D882-09. The data were collected and analyzed using Testworks 8.0. ${ }^{1} \mathrm{H}$ NMR spectra were recorded on a Bruker instrument operating at $300.152 \mathrm{MHz}$. Material 
surfaces were imaged using a Zeiss LSM 5 Exciter confocal microscope and an Olympus BH-2 optical microscope equipped with a Hitachi KP-D50 digital color camera. Water contact angle data were collected using a First Ten Angstroms FTA 1000B contact angle goniometer. Tilting axis contact angles were measured for each sample using an $8 \mu \mathrm{L}$ water droplet. Interfacial tension measurements of a suspended water drop were made prior to experimentation to verify water purity and precision of the focused image. Contact angles were determined by drop shape analysis from a series of images collected at a rate of 2 frames/s. The stage of the contact angle instrument was tilted at a rate of $2 \%$ s to an inclination of $60^{\circ}$. A minimum of two measurements were recorded for each sample. Attenuated total reflection infrared (ATR-IR) spectra were recorded with a Thermo Nicolet IR300 spectrometer. The lunar dust simulant used in this work was NASA/USGS Lunar Highland simulant, maximum particle diameter $<30 \mu \mathrm{m}$.

\subsection{Polyimide Synthesis}

Homopolyimides prepared by the condensation reaction of stoichiometric equivalents of aromatic dianhydride and aromatic diamine were used as controls. To prepare the homopolyimides, a reaction vessel was flushed with nitrogen for 10 minutes prior to the addition of reactants. Reactions were carried out under nitrogen at 20 wt. $\%$ solids in $N$ methylpyrrolidinone (NMP). The diamine (typically 7 to $10 \mathrm{mmol}$ ) was dissolved in NMP (typically $15 \mathrm{~mL}$ ), to which the dianhydride (in an appropriate quantity to achieve a stiochiometric equivalence with the total diamine addition) was added, followed by additional NMP (for a total of $40 \mathrm{~mL}$ ), and the reaction mixture was mechanically stirred overnight. Inherent viscosities $\left(\eta_{\text {inh }}\right)$ were determined at $25^{\circ} \mathrm{C}$ on the poly(amide acid) solutions using an Ubbelohde viscometer and solution concentrations of $0.5 \mathrm{~g} \mathrm{dL}^{-1}$. Films were subsequently cast on plate glass using a doctor blade and placed in a forced air-drying chamber until tack-free. Films were then thermally imidized under nitrogen using a cure cycle with stages at 150,175 , 200 , and $250{ }^{\circ} \mathrm{C}$, with at least a $40 \mathrm{~min}$ hold at each temperature. The films were removed from the glass and used to perform the various characterizations and tests described herein.

Copoly(imide siloxane)s were prepared similarly, except a solvent mixture of 4:1 NMP and tetrahydrofuran (THF) was used. The PDMS component (10 wt. \% of the total solids, typically 0.03 to $4 \mathrm{mmol}$ ) was dissolved in THF (11 mL with the total NMP addition reduced to $30 \mathrm{~mL}$ ) and added to the reaction vessel with the diamine. Inherent viscosities $\left(\eta_{\text {inh }}\right)$ were determined for 
the copoly(amide acid) solutions as described above. Films were cast and thermally imidized as before, save for the use of polished stainless steel plates because the copoly(amide acid siloxane) films could not be removed from glass plates without tearing.

\subsection{Laser Ablation Patterning}

A $0^{\circ} / 90^{\circ}$ crosshatch pattern was etched into polymer film surfaces $\left(1 \mathrm{~cm}^{2}\right)$ using a PhotoMachining, Inc. laser ablation system equipped with a Coherent Avia ${ }^{\circledR}$ frequency-tripled Nd:YAG laser $(\lambda=355 \mathrm{~nm}, 7 \mathrm{~W})$.(Wohl et al., 2010b) The laser pulse energy, frequency, diameter, and scan speed were kept constant at $3 \mu \mathrm{J} /$ pulse, $80 \mathrm{kHz}, 25 \mu \mathrm{m}$ and $25.4 \mathrm{~cm} / \mathrm{s}$, respectively, and line spacing was maintained at $25 \mu \mathrm{m}$. The pattern was transcribed over the surface four times.

\subsection{Adhesion Testing}

Particle adhesion testing was performed using a sonication device (VCX-750, Sonics and Materials, Inc.). A polymer film sample was adhered to the end of a sonic wand tip using an acrylic adhesive. Lunar dust simulant (NASA/USGS Lunar Highland simulant, maximum particle diameter $<30 \mu \mathrm{m}$ ) was deposited on the polymer surface by placing the polymer film in a plastic bag containing the simulant. Agitation of the bag caused simulant to become airborne and deposit on the film surface. The particle deposition was characterized using an optical microscope. Measurement of the adhesive interactions between the particles and the substrate required no greater deposition than a monolayer of particles; if the deposition of particles resulted in stacked or multi-layered particle deposits, the surface was cleaned with a dust-free cloth and the deposition process was repeated. Activation of the sonic wand induced vibration at the tip that resulted in an acceleration force acting normal to the sample plane, $F_{a c c}$, determined by the mass of the particle, $m$, and the acceleration of the tip, $a$. The latter is related to the frequency of oscillation, $\omega$, and the amplitude of displacement, $A$. By variation of the sonic wand's vibrational amplitude, particles were dislodged from the polymer film surface when $F_{a c c}$ was equal to or greater than the adhesion force, $F_{\text {adh }}(\mathbf{E q . ~ 1 )}$,

$$
F_{a c c}=m a=m\left(4 \pi^{2} \omega^{2} A\right) \geq F_{a d h}
$$


. This relationship assumes that change in the acceleration of the sonic wand follows a sinusoidal pattern. Since these measurements were conducted in the vertical orientation, the gravitational force acting normal to the plane was also included, although its magnitude was negligible compared to the adhesion forces. Particles were assumed to be spherical with a density of $2.9 \mathrm{~g}$ $\mathrm{cm}^{-3}$.(McKay et al., 1994) Variation of sonic wand amplitude from $12.2-48.8 \mu \mathrm{m}$ corresponded to surface acceleration values from $380-1550 \mathrm{~km} \mathrm{~s}^{-2}$. After completion of adhesion testing, samples were removed from the device assembly and observed under the optical microscope to characterize particles remaining adhered to the surface. For the materials investigated here, lunar simulant particles remained on the surface upon completion of the experiments. Minimum adhesion force values were calculated according to the size of the particles remaining on the polymer film surface at the completion of the sonication sequence (i.e., for these particles $F_{a d h}$ exceeded the $F_{\text {acc }}$ provided by sonication).

\section{RESULTS AND DISCUSSION}

Siloxane oligomers were obtained commercially from Gelest with molecular weights reported in Table 1. ${ }^{1} \mathrm{H}$ NMR analysis was performed on the oligomers to determine molecular weight by calculating the ratio of methylene protons of the aminopropyl groups to the methyl groups on the siloxane repeat units. This type of end-group analysis typically has errors $\leq 5 \%$.(Hatada and Kitayama, 2004) The results were comparable to the manufacturer's data for the S1 and S3 oligomers but notable differences were present for the other 3 oligomers (Table 1).

Table 1. Molecular weights for the siloxane materials.

\begin{tabular}{|l|ccc|c|}
\hline & \multicolumn{3}{|c|}{ Molecular Weight $\left(\mathrm{g} \mathrm{mol}^{-1}\right)$} & Number of repeat \\
Siloxane & Designation & Reported & ${ }^{1} \mathrm{H} \mathrm{NMR}$ Analysis & units \\
\hline Disiloxane & S1 & 249 & 249 & 1 \\
DMS-A11 & S2 & 875 & 1150 & 12 \\
DMS-A15 & S3 & 3000 & 2980 & 37 \\
DMS-A21 & S4 & 5000 & 6150 & 80 \\
DMS-A32 & S5 & 30000 & 35800 & 480 \\
\hline
\end{tabular}




\subsection{Polymer Synthesis and Characterization}

Homopolyimides were prepared to serve as controls for comparison to the properties of the copoly(imide siloxane)s in the various characterizations and tests performed herein (Scheme 1). Copoly(imide siloxane)s were synthesized in a manner similar to the homopolyimides with the noted difference that a mixed solvent system of THF:NMP (approximately 1:3 by weight) was used for solvation of the siloxane oligomers. A general structure of the copoly(imide siloxane)s is shown in Scheme 2.

Scheme 1. Polyimide synthesis and monomer structures. Common abbreviations for these monomers are adjacent to the structures.

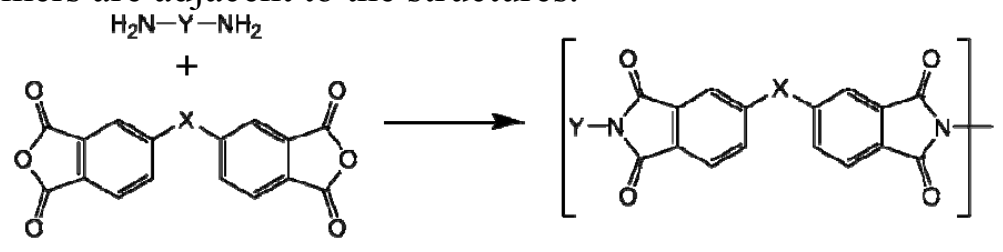

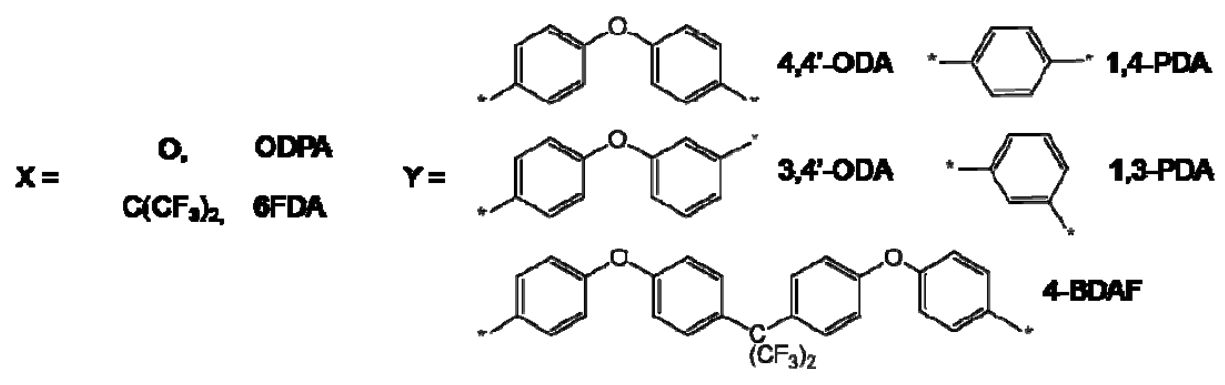

Scheme 2. Representative idealized random copoly(imide siloxane) structure.

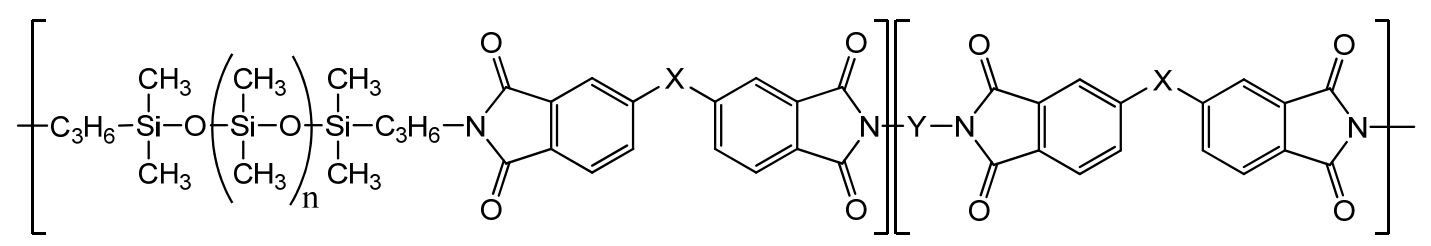

For simplicity, the copoly(imide siloxane)s have been assigned designations based on their monomeric compositions. Names for the siloxane component can be found in Table 2 and the definition of the different polyimide monomeric compositions are provided in Scheme 1. For 
example, a polymer synthesized from 6FDA and 4,4'-ODA without the addition of a siloxane component was assigned the designation P1S0, while a polymer comprised of the same two monomers with the addition of the PDMS with a molecular weight of $2980 \mathrm{~g} \mathrm{~mol}^{-1}$ was labeled P1S3. Inherent viscosity measurements were performed on the poly(amide acid) solutions. (Table 2). The addition of disiloxane usually led to a lower inherent viscosity of the polyamide acid solution.

Table 2. Copoly(imide siloxane) designations and inherent viscosity values. For dianhydride and diamine structures, refer to Scheme 1.

\begin{tabular}{|c|c|c|c|c|c|}
\hline $\begin{array}{l}\text { Copolymer } \\
\text { Designation }\end{array}$ & Dianhydride & Diamine & $\begin{array}{l}\text { Siloxane } \\
\text { Oligomer }\end{array}$ & $\begin{array}{c}\eta_{\text {inh }} \\
\mathrm{dL} \mathrm{g}^{-1}\end{array}$ & $\begin{array}{c}\text { Film } \\
\text { Opacity }\end{array}$ \\
\hline P1S0 & 6FDA & $4,4^{\prime}$-ODA & None & 1.42 & Transparent \\
\hline P1S1 & 6FDA & $4,4^{\prime}-\mathrm{ODA}$ & Disiloxane & 0.21 & Transparent \\
\hline P1S2 & 6FDA & $4,4^{\prime}-\mathrm{ODA}$ & DMS-A11 & 0.91 & Transparent \\
\hline P1S3 & 6FDA & $4,4^{\prime}$-ODA & DMS-A15 & 0.95 & Opaque \\
\hline P1S4 & $6 \mathrm{FDA}$ & $4,4^{\prime}-\mathrm{ODA}$ & DMS-A21 & 1.28 & Opaque \\
\hline P1S5 & $6 \mathrm{FDA}$ & 4,4'-ODA & DMS-A32 & 1.14 & Opaque \\
\hline $\mathrm{P} 2 \mathrm{~S} 0$ & $6 \mathrm{FDA}$ & $3,4^{\prime}-\mathrm{ODA}$ & None & 0.94 & Transparent \\
\hline $\mathrm{P} 2 \mathrm{~S} 1$ & $6 \mathrm{FDA}$ & $3,4^{\prime}-\mathrm{ODA}$ & Disiloxane & 0.33 & Transparent \\
\hline $\mathrm{P} 2 \mathrm{~S} 2$ & 6FDA & $3,4^{\prime}-\mathrm{ODA}$ & DMS-A11 & 0.65 & Opaque \\
\hline $\mathrm{P} 2 \mathrm{~S} 3$ & 6FDA & $3,4^{\prime}$-ODA & DMS-A15 & 0.76 & Opaque \\
\hline $\mathrm{P} 2 \mathrm{~S} 4$ & $6 \mathrm{FDA}$ & $3,4^{\prime}-\mathrm{ODA}$ & DMS-A21 & 1.03 & Opaque \\
\hline P2S5 & $6 \mathrm{FDA}$ & $3,4^{\prime}-\mathrm{ODA}$ & DMS-A32 & 0.86 & Opaque \\
\hline P3S0 & $6 \mathrm{FDA}$ & 1,4-PDA & None & 0.87 & Transparent \\
\hline P3S1 & 6FDA & 1,4-PDA & Disiloxane & 0.66 & Transparent \\
\hline P3S2 & 6FDA & 1,4-PDA & DMS-A11 & 0.93 & Transparent \\
\hline P3S3 & 6FDA & 1,4-PDA & DMS-A15 & 1.04 & Opaque \\
\hline P3S4 & 6 FDA & 1,4-PDA & DMS-A21 & 0.73 & Opaque \\
\hline P3S5 & $6 \mathrm{FDA}$ & 1,4-PDA & DMS-A32 & 1.05 & Opaque \\
\hline $\mathrm{P} 4 \mathrm{~S} 0$ & 6FDA & 1,3-PDA & None & 0.74 & Transparent \\
\hline P4S1 & 6FDA & 1,3-PDA & Disiloxane & 0.53 & Transparent \\
\hline $\mathrm{P} 4 \mathrm{~S} 2$ & 6FDA & 1,3-PDA & DMS-A11 & 0.76 & Transparent \\
\hline P4S3 & 6FDA & 1,3-PDA & DMS-A15 & 0.66 & Opaque \\
\hline P4S4 & 6FDA & 1,3-PDA & DMS-A21 & 0.35 & Opaque \\
\hline P4S5 & $6 \mathrm{FDA}$ & 1,3-PDA & DMS-A32 & 0.67 & Opaque \\
\hline $\mathrm{P} 5 \mathrm{~S} 0$ & 6FDA & 4-BDAF & None & 1.18 & Transparent \\
\hline P5S1 & $6 \mathrm{FDA}$ & 4-BDAF & Disiloxane & 0.70 & Transparent \\
\hline P5S2 & 6FDA & 4-BDAF & DMS-A11 & 0.95 & Opaque \\
\hline P5S3 & 6FDA & 4-BDAF & DMS-A15 & 0.78 & Opaque \\
\hline P5S4 & 6FDA & 4-BDAF & DMS-A21 & 1.28 & Opaque \\
\hline P5S5 & $6 \mathrm{FDA}$ & 4-BDAF & DMS-A32 & 1.09 & Opaque \\
\hline $\mathrm{P} 6 \mathrm{~S} 0$ & ODPA & $4,4^{\prime}-\mathrm{ODA}$ & None & 1.21 & Transparent \\
\hline P6S4 & ODPA & $4,4^{\prime}-\mathrm{ODA}$ & DMS-A21 & 0.50 & Opaque \\
\hline
\end{tabular}


There were some slight differences in how these homopolymer and copolymer films were prepared compared to typical polyimide generation procedures. For example, since the siloxane units contain aliphatic carbons, steps were taken to minimize any thermal degradation during imidization by conducting this reaction under a nitrogen atmosphere at a lower temperature (250 $\left.{ }^{\circ} \mathrm{C}\right)$ than is typically used for aromatic polyimides $\left(300{ }^{\circ} \mathrm{C}\right)$. The incorporation of smaller siloxane moieties was found to preserve the visual transparency of the copolymer film, while incorporation of siloxane oligomers $2980 \mathrm{~g} \mathrm{~mol}^{-1}$ or higher resulted in visually opaque films, suggesting that the copolymer was phase segregated (Table 2, Figure 1). Phase segregation in similar copolymers has previously been observed, and the segregated domains were visualized using various microscopic techniques.(Fitzgerald et al., 1993; Ghosh and Banerjee, 2008; Ku and Lee, 2007; Patel et al., 1988; Samseth et al., 1992)

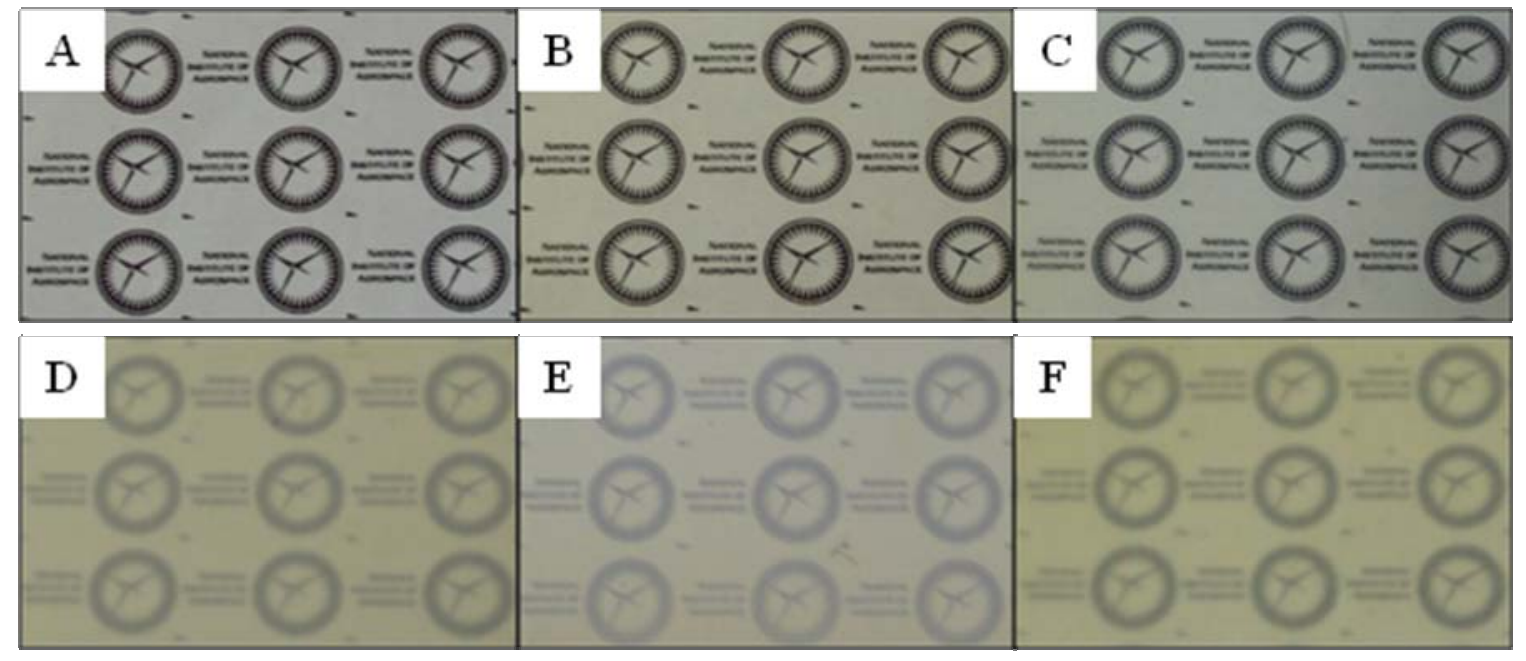

Figure 1. Transparency of the polymer films exhibited dependence on siloxane oligomer length as can be seen for: (A) P4S0, (B) P4S1, (C) P4S2, (D) P4S3, (E) P4S4, and (F) P4S5.

Imidization of the copolymer films was verified by ATR-IR spectroscopy (data not shown). Bands assigned to imide functionalities were observed at 1778 and $1725 \mathrm{~cm}^{-1}$. The amide acid band at $1546 \mathrm{~cm}^{-1}$ was absent in the spectra collected from thermally imidized copolymer films. Vibrational bands assignable to PDMS moieties within the copolymer matrix were observed at 1025 and $798 \mathrm{~cm}^{-1}$, corresponding to $\mathrm{Si}-\mathrm{O}-\mathrm{Si}$ and $\mathrm{Si}-\mathrm{CH}_{3}$ functionalities, respectively. To evaluate the relative surface concentration of the siloxane oligomers qualitatively, difference spectra were calculated via subtraction of the homopolyimide spectrum from each of the 
copoly(imide siloxane) spectra for the P5 (6FDA:4-BDAF) copolymer series. The absorbance values for each copoly(imide siloxane) spectrum were scaled to the $1725 \mathrm{~cm}^{-1}$ imide absorption value from the homopolyimide spectrum and the absorbance values for the two siloxane vibrational bands are shown in Figure 2. Both of the bands associated with the siloxane segment exhibit a significant increase in absorbance up to a siloxane oligomer molecular weight of $1150 \mathrm{~g}$ $\mathrm{mol}^{-1}$ (the S2 oligomer) with copolymers synthesized from longer siloxane oligomers not exhibiting significantly higher absorption intensities. As ATR-IR has a typical sampling depth of approximately 1 micron,(Chan, 1994) these observations may result from an averaging between the surface and bulk composition. However, the results do indicate that the surface concentration of siloxane species is dependent on siloxane oligomer length up to an apparent saturation limit. More quantitative data regarding the siloxane surface concentration can be obtained using contact angle goniometry, as described below.

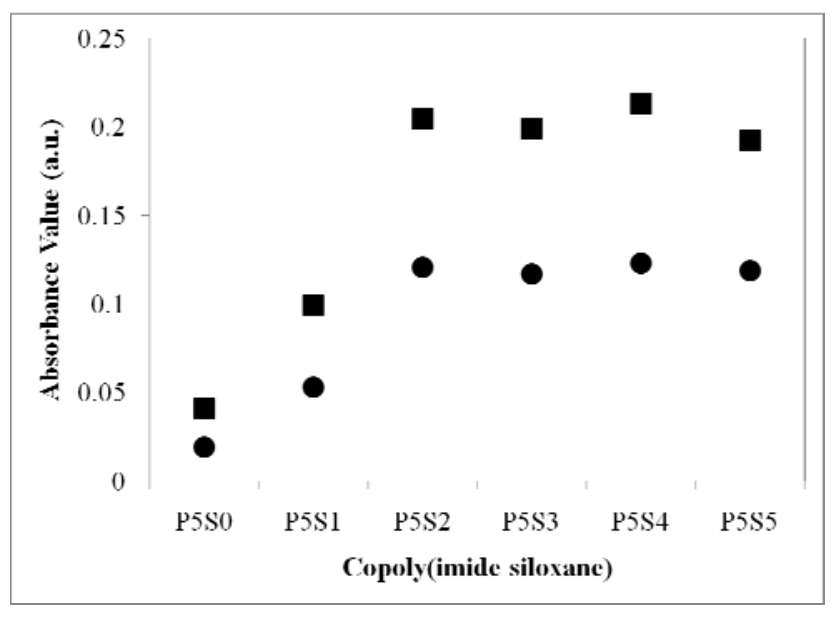

Figure 2. ATR-IR absorbance values for copoly(imide siloxane) spectra at $798 \mathrm{~cm}^{-1}$ (squares) and $1025 \mathrm{~cm}^{-1}$ (circles) associated with $\mathrm{Si}-\mathrm{O}-\mathrm{Si}$ and $\mathrm{Si}-\mathrm{CH}_{3}$ functionalities, respectively.

\subsubsection{Thermal Properties}

Thermal properties of a material often provide insight into structure and long range order phenomena within the bulk material. DSC and DMA were used to understand how the incorporation of siloxane oligomers affected these processes within a polyimide matrix. The change in heat capacity upon progression through the glass transition temperature, $T_{g}$, was not significant for several of the homopolyimides generated here, making detection by DSC difficult. This problem was exacerbated by the addition of siloxane moieties, resulting in the absence of a 
detectable $\mathrm{T}_{\mathrm{g}}$ by DSC for a majority of the copoly(imide siloxane) materials. Fortunately, reliable data was collected for the full series of the P5 (6FDA:4-BDAF) polymeric materials. Although the $T_{g}$ values for the imide portion of the copoly(imide siloxane)s were readily detected for this series, the glass transitions were not reliably measured for the siloxane segment. Therefore, DMA measurements were collected on this series and the results of both analyses are presented in Table 3. The $T_{g}$ values associated with the siloxane segment did not demonstrate a significance on the siloxane segment length, as has been determined previously for similar systems.(Fitzgerald et al., 1993) The imide $T_{g}$ value, however, varied significantly depending on which siloxane oligomer was present in the copoly(imide siloxane). Smaller siloxane moieties resulted in significant $T_{g}$ value reductions, while larger siloxane components resulted in less dramatic changes. This is further evidence that larger siloxane oligomers exhibited greater phase separation within the polyimide matrix, which coincides with the differences observed in optical transparency. In a related study by Feng, et al., the change in heat capacity for a series of copoly(styrene siloxane) materials indicated that the degree of phase mixing (DPM) was dependent on siloxane segment lengths (with larger segment lengths exhibiting lower DPM values) similar to the results presented here.(Feng et al., 1989) A similar dependence on the siloxane oligomer length was observed for $\beta$ transitions, which were assigned to the imide segments of the copolymer.(Sun et al., 1992)

Table 3. Copoly(imide siloxane) thermal properties determined by DSC and DMA.

\begin{tabular}{cccc|c} 
& \multicolumn{3}{c|}{ DMA, ${ }^{\circ} \mathrm{C}$} & \multirow{2}{*}{$\mathrm{DSC},{ }^{\circ} \mathrm{C}$} \\
\cline { 2 - 4 } Copolymer & \multicolumn{3}{c}{$\beta$ Relaxation, } \\
Designation & $\mathrm{T}_{\mathrm{g}}$, Siloxane & Imide & $\mathrm{T}_{\mathrm{g}}$, Imide & \multirow{2}{*}{$\mathrm{T}_{\mathrm{g}}$, Imide } \\
\hline P5S0 & -- & 102 & 262 & 262 \\
P5S1 & Not detected & 77 & 199 & 195 \\
P5S2 & -117 & 80 & 235 & 230 \\
P5S3 & -121 & 83 & 257 & 255 \\
P5S4 & -122 & 95 & 263 & 258 \\
P5S5 & -123 & 100 & 265 & 262
\end{tabular}

\subsubsection{Film Tensile Properties}

As can be anticipated, the addition of siloxane oligomers resulted in a decrease in the modulus for all of the investigated copoly(imide siloxane) film samples (Figure 3A). Furthermore, within 
each polyimide type, larger siloxane functionalities resulted in greater reductions in modulus. The trend observed in this data suggested that a minimal modulus value (approximately $75 \%$ of the homopolyimide value) was obtained upon increase of the siloxane molecular weight to 6150 $\mathrm{g} \mathrm{mol}^{-1}$.

The ultimate percent elongation, which is an indicator of the elastic/inelastic deformation capability of the polymeric material, was also determined for the copoly(imide siloxane) films (Figure 3B). The addition of siloxane moieties increased the elastic/inelastic deformation length for all of the polyimide matrices studied. The data are displayed as change in the percent elongation values relative to the corresponding homopolyimide material due to the large disparity between polyimide matrices. For example, materials generated from the P2 polyimide matrix exhibited percent elongation values of 9 and $19 \%$ for siloxanes S0 and S3, respectively, while the P3 materials elongated 3 and $10 \%$ for the same siloxane additions. For copolymers containing low molecular weight siloxanes, the percent elongation value was considerably larger than the homopolymer (as high as $290 \%$ ). Increased siloxane molecular weight actually resulted in a decrease in this effect with copolymers containing the S5 siloxane demonstrating the lowest increase in percent elongation.
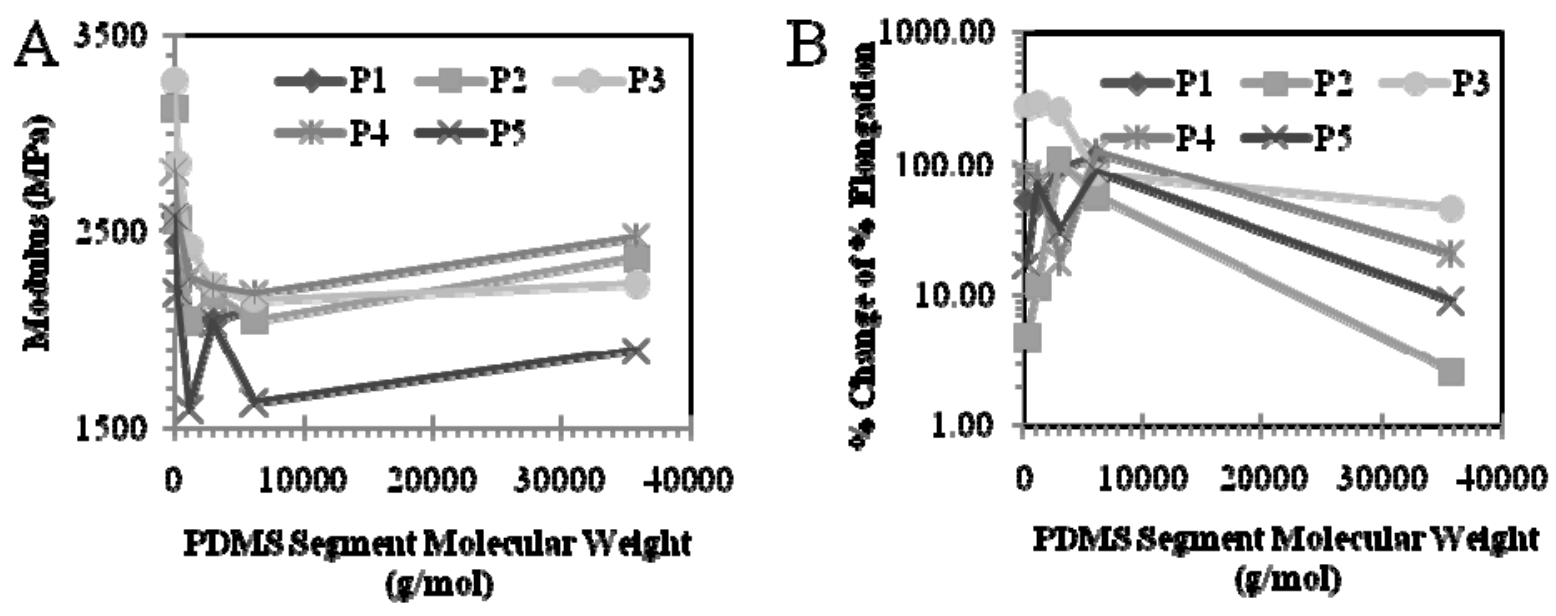

Figure 3. Plot of tensile modulus (A) and percent elongation (B) versus siloxane segment length. The lines are included only as guides. 


\subsubsection{Contact Angle Analysis}

The surface energy of a material is one of several indicators of the likelihood for adhesive interaction with contaminants through non-mechanical interactions (chemical vs. physical attachment), where surfaces with lower surface energies would be anticipated to exhibit reduced adhesive interactions. The surface energy of a material can be determined by measuring the contact angle of solvents with known surface tension. Higher contact angle values correlate with lower surface energies. The measurement of solvent droplet contact angles, contact angle goniometry, is specific to surface properties with a sampling depth of only a few nanometers.

Water contact angles were collected from images of $8 \mu \mathrm{L}$ drops deposited on the copolymer film surfaces (Figure 4). Advancing water contact angle values, $\theta_{\mathrm{adv}}$, measured on copoly(imide siloxane) film surfaces were larger with increased siloxane molecular weight. Copoly(imide siloxane)s generated with the S5 siloxane $\left(35,800 \mathrm{~g} \mathrm{~mol}^{-1}\right)$ exhibited the greatest $\theta_{\text {adv }}$ values and in some cases surpassed that of Teflon ${ }^{\circledR}\left(\theta_{\mathrm{adv}} \sim 110^{\circ}\right)$, approaching values measured on PDMS surfaces, $119^{\circ}$. This increase in $\theta_{\mathrm{adv}}$ values suggests a preferential segregation of the siloxane moieties to the polymer surface in agreement with results obtained from ATR-IR described previously. The data also suggest that $\theta_{\text {adv }}$ might increase further with incorporation of larger siloxane moieties. This is unlikely, however, as the $\theta_{\mathrm{adv}}$ values are already approaching, and exceeding in some cases, $\theta_{\text {adv }}$ measured on a hexagonally oriented CF3 coated surface $\left(119^{\circ}\right)$, a surface with theoretically the lowest possible surface energy.(Nishino et al., 1999). $\theta_{\mathrm{adv}}$ values measured in excess of $119^{\circ}$ for the copoly(imide siloxane) films discussed here are likely the result of unintended topographical features on the $\mathrm{nm}$ scale resultant from the thermal imidization process. A further reduction in the surface energy, i.e., $\theta_{\mathrm{adv}}$ values greater than $119^{\circ}$, required a reduction in the interaction area, which was achieved via topographical modification as described below. 


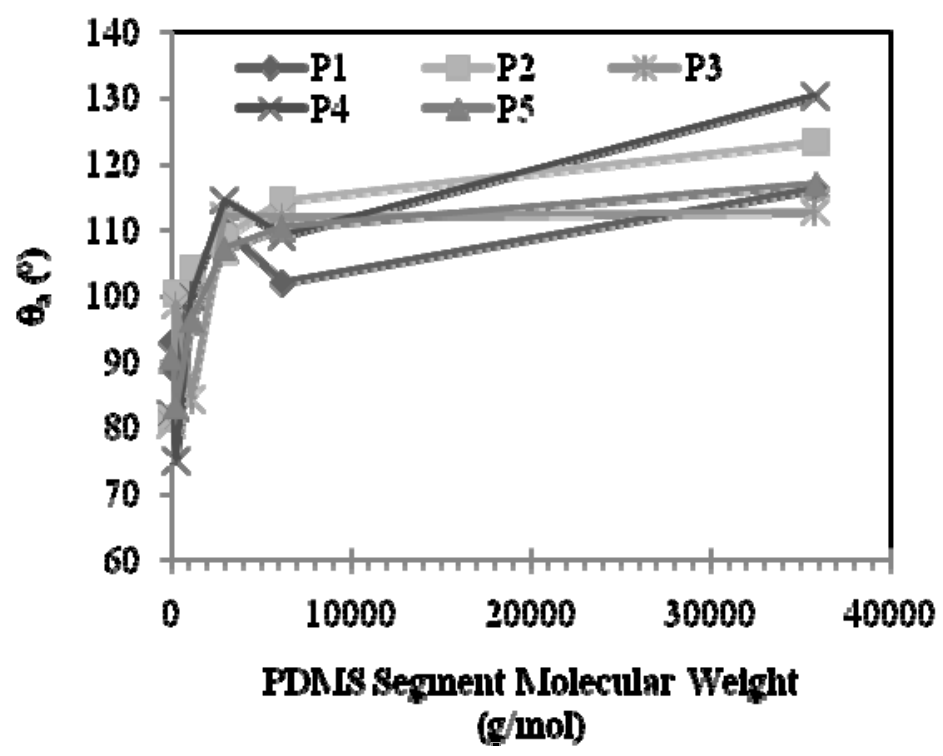

Figure 4. Water contact angles for copoly(imide siloxane)s versus siloxane segment length.

\subsection{Laser Ablation Patterning}

As water contact angles indicated (Figure 4), generation of copoly(imide siloxane) materials greatly reduced the material's surface energy and implicitly, the adhesive interactions with contaminating particles . To further increase $\theta_{\mathrm{adv}}$ values (and reduce the surface energy to a greater extent), the surfaces were topographically modified using a laser ablation system. Laser ablation affords a precise, high fidelity process with several adjustable parameters enabling transcription of a variety of patterns. A simple $0^{\circ} / 90^{\circ}$ crosshatch pattern was utilized here. The settings necessary to generate topographical features several microns in height on copolymer film surfaces was determined in previous work.(Wohl et al., 2010a) They were $3 \mu \mathrm{J} /$ pulse at a frequency of $80 \mathrm{kHz}$ and scan speed of $25.4 \mathrm{~cm} \mathrm{~s}^{-1}$. The crosshatch pattern was transcribed onto the surface four times to increase the ablation depth. Highly accurate sample alignment enabled several transcription steps to be performed on a sample surface with nearly exact overlap of previous steps. Optical and confocal micrographs verified the fidelity of this process over large length scales (Figure 5). Although not shown here, this approach was adopted to transcribe patterns several centimeters in extent into copoly(imide siloxane) films. 

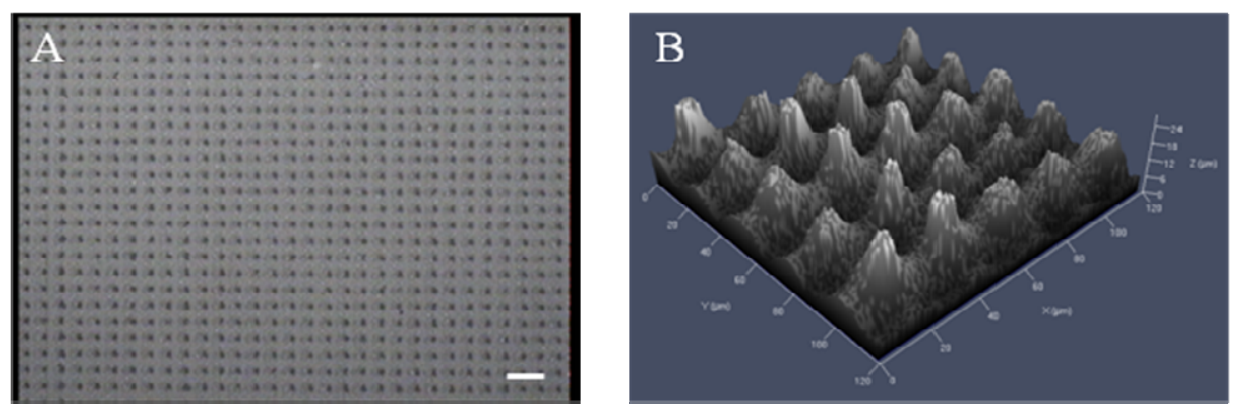

Figure 5. Optical (A) and confocal (B) micrographs of a laser ablation patterned P2S3 surface. The scale bar in A is $50 \mu \mathrm{m}$.

The introduction of topographies resulted in increased water $\theta_{\mathrm{adv}}$ values for all materials investigated here. Figure 6 provides an example of the increase in $\theta_{\text {adv }}$ values for a hompolyimide (P1S0, top) and a copoly(imide siloxane) (P1S4, bottom). The increase in $\theta_{\mathrm{adv}}$ was greater for the copolymeric materials than for the homopolyimide surfaces except for copolymers that incorporated the $\mathrm{S} 1$ siloxane. The $\theta_{\mathrm{adv}}$ values determined for the laser ablation patterned surfaces were classified as superhydrophobic $\left(\theta_{\mathrm{adv}} \geq 150^{\circ}\right)$, and in some cases approached $180^{\circ}$. The $\theta_{\mathrm{adv}}$ values for several copoly(imide siloxane)s are shown in Figure 7.

Although large $\theta_{\mathrm{adv}}$ values are indicative of low surface energies, there are examples in the literature where water droplets strongly adhered to a superhydrophobic surface.(Winkleman et al., 2008) Roll-off angles are further indications of the tendency of particles to adhere to surfaces, since a low roll-off angle indicates that the incident solvent does not wet the surface. Although not shown, the roll-off angles for several laser ablation patterned copoly(imide siloxane)s were $<10^{\circ}$, with roll-off angles as low as $2^{\circ}$ observed, strongly suggesting that laser ablation patterned copoly(imide siloxane) surfaces may exhibit less particulate adhesion compared to non-patterned surfaces. 


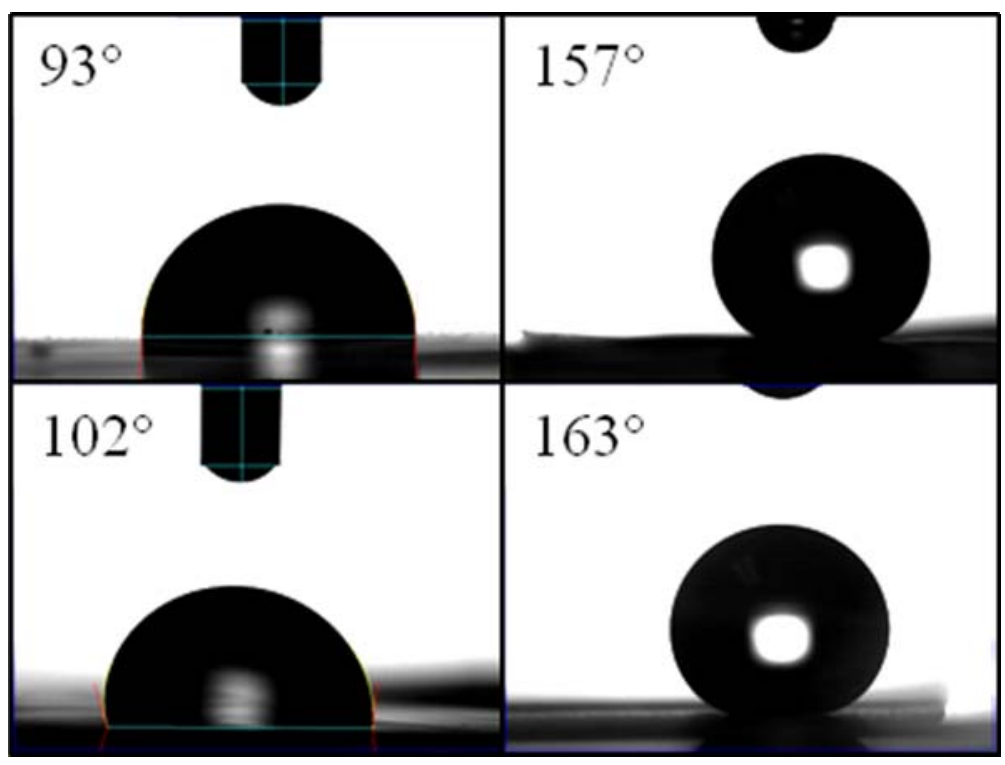

Figure 6. Images of water drops used to determine contact angles observed on P1S0 (top, homopolyimide) and P1S4 [bottom, copoly(imide siloxane)], before (left) and after (right) laser ablation patterning.

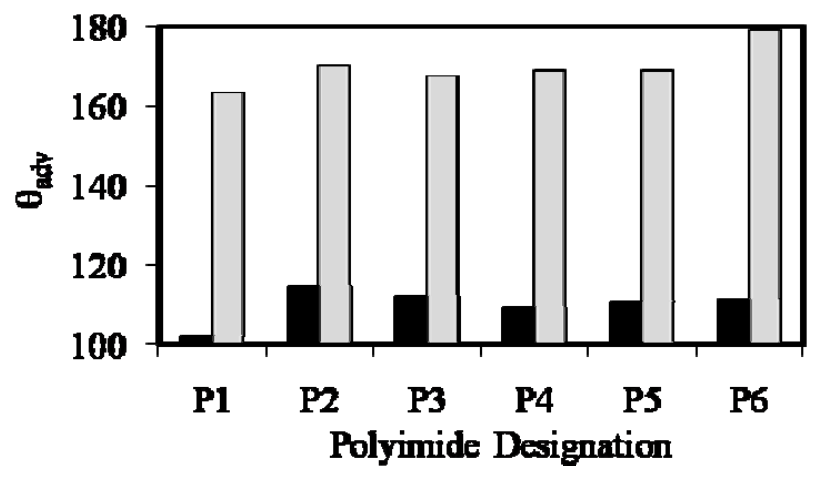

Figure 7. Comparison of contact angles of pristine copoly(imide siloxane) surfaces (black) with laser ablation patterned surfaces (gray). Data corresponds to copolymers generated with S4 except for P3 and P4, which contain the S3 siloxane moiety.

\subsection{Particle Adhesion Testing}

As mentioned previously, it was of interest to establish a correlation between the surface energy of the various materials prepared herein and the magnitude of adhesive interactions with particles. Preliminary particle adhesion experiments were conducted by agitation of a lunar dust 
simulant-contaminated polymer surface via sonication. Similar studies have demonstrated that meaningful relationships between particle size and adhesion strength can be determined using this technique.(Mullins et al., 1992) Particles that remained adhered to the polymer surface (i.e., $F_{a d h} \geq F_{a c c}$ ) were observed using optical microscopy (Figure 8) and the size of these particles was used to calculate a minimum adhesion force based on the amplitude setting of the sonic wand (see Eq. 1). For comparative purposes, a commercially available polyimide (Kapton ${ }^{\circledR} \mathrm{HN}$, Du Pont de Nemours and Company, Inc.) was tested along with a copoly(imide siloxane) and a laser ablation patterned copoly(imide siloxane) film sample. The number of particles remaining on the surface within the optical micrograph and minimum adhesion force for each surface is indicated in Table 4. The copoly(imide siloxane) material had a demonstrated decrease in both particle count and adhesion force relative to Kapton ${ }^{\circledR}$ HN. Laser ablation patterning further reduced the number of adhered particles and the adhesion force.

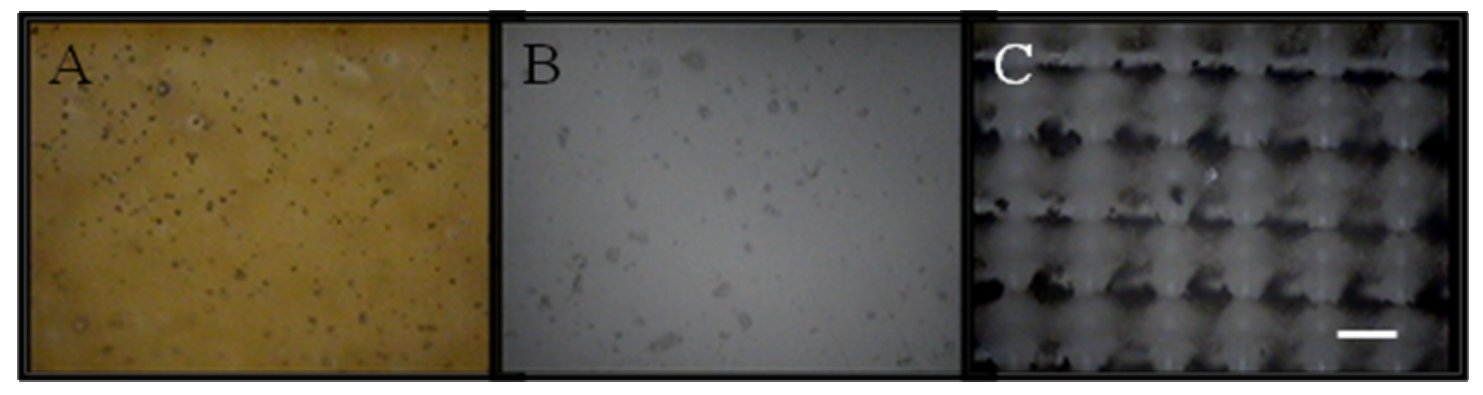

Figure 8. Sonic wand adhesion testing indicated that the polyimide surface (A) retained a greater number of particles than the copoly(imide siloxane) surface both before (B) and after laser ablation patterning (C). The lunar simulant particle retained on the laser ablation patterned surface can be seen near the center of the image. The scale bar is $25 \mu \mathrm{m}$ and the magnification is the same for each image.

Table 4. Particle Adhesion Results.

\begin{tabular}{ccc} 
Material & Particle Count & $\begin{array}{c}\text { Minimum Adhesion } \\
\text { Force, } \mathbf{n N}\end{array}$ \\
\hline Kapton ${ }^{\circledR} \mathrm{HN}$ & $\sim 378$ & 156 \\
P1S4 & $\sim 252$ & 112 \\
Laser Patterned P1S4 & $1-2$ & $10-68$
\end{tabular}




\section{CONCLUSIONS}

In this work, low surface energy copoly(imide siloxane)s were generated with various siloxane segment lengths. Characterization of these materials revealed that domain formation of the low surface energy component within the matrix was more prevalent for longer siloxane segments as indicated by increased opacity, decreased mechanical properties, and variation of the glass transition temperature. Incorporation of siloxanes lowered the polymer's surface energy as indicated by water contact angle values. Topographical modification of these materials by laser ablation patterning further reduced the surface energy, in some cases generating superhydrophobic surfaces.

Combined, the water contact angle data and particle adhesion testing suggested that copoly(imide siloxane) materials do provide lower particulate adhesion than polyimide materials alone. However, the enhanced surface properties for abhesive applications were generated to the detriment of the copolymers' moduli. It is possible that lower siloxane loading levels would result in retention of the mechanical properties of the polyimide while still affording abhesive surface properties and this approach is currently being investigated. Laser ablation patterning offers further reduction in particle retention as the available surface area for particle adhesion is reduced. Pattern variation and size dependencies are currently being evaluated.

It is feasible that combining these materials with active mitigation strategies - methods that require external energy sources - would broaden the applicability of such materials for abhesive purposes. Collaborative efforts along these lines have been initiated with researchers at NASA Kennedy Space Center where experiments are being conducted involving a series of embedded electrodes within polymeric matrices.(Calle et al., 2010; Immer et al., 2006)

\section{ACKNOWLEDGEMENTS}

The authors would like to thank Dr. Jeffrey A. Hinkley, NASA Langley Research Center, for scientific discussion. This work was funded through the NASA Langley Research Center's Creative and Innovative Research Fund. 


\section{REFERENCES}

(1) (1990); Polyimides. New York: Chapman and Hall.

(2) Abbas, M., Tankosic, D., Craven, P., Spann, F., LeClair, A. and West, E. (2007) 'Lunar Dust Charging by Photoelectric Emissions,' Planet. Space Sci., 55: 953 - 965.

(3) Borisov, N. and Mall, U. (2006) 'Charging and Motion of Lunar Dust Grains near the Terminator of the Moon,' Planet. Space Sci., 54: 572 - 580.

(4) Calle, C. I., Buhler, C. R., Hogue, M. D., Johansen, M. R., Cruz, V. B., Hopkins, J. W., Holloway, N. M. H., Connell, J. W., Chen, A., Irwin, S. A., Case, S. O., Van Suetendael, N. J., Snyder, S. J. and Clements, J. S. (Year) 'Active Dust Mitigation Technology for Thermal Radiators for Lunar Exploration,' Earth and Space 2010 Conference, Honolulu, HI.

(5) Chan, C.-M. (1994); Polymer Surface Modification and Characterization. Munich: Carl Hanser Verlag.

(6) Colwell, J. E., Batiste, S., Horanyi, M., Robertson, S. and Sture, S. (2007) 'Lunar Surface: Dust Dynamics and Regolith Mechanics,' Rev. Geophys., 45: 2005RG000184.

(7) Feng, D., Wilkes, G. L. and Crivello, J. V. (1989) 'Structure-Property Behavior of Free Radical Synthesized Polydimethylsiloxane-Polystyrene Multiblock Polymers: 1. Effect of the Siloxane Block Length,' Polymer, 30: 1800 - 1813.

(8) Fischer, H., Tempelaars, K., Kerpershoek, A., Dingemans, T., Iqbal, M., van Lonkhuyzen, H., Iwanowsky, B. and Semprimoschnig, C. (2010) 'Development of Flexible LeoResistant Pi Films for Space Applications Using a Self-Healing Mechanism by Surface-Directed Phase Separation of Block Copolymers,' ACS Applied Materials and Interfaces, 2: 2218-2225.

(9) Fitzgerald, J., Tunney, S. and Landry, M. (1993) 'Synthesis and Characterization of a Fluorinated Poly(Imide-Siloxane) Copolymer: A Study of Physical Properties and Morphology,' Polymer, 34: 1823-1832.

(10) Ghosh, A. and Banerjee, S. (2008) 'Synthesis, Characterization, and Comparison of Properties of Novel Fluorinated Poly(Imide Siloxane) Copolymers,' J. Appl. Polym. Sci., 107: 1831-1841.

(11) Halekas, J., Lin, R. and Mitchell, D. (2007) 'Large Negative Lunar Surface Potentials in Sinlight and Shadow,' Geophys. Res. Lett., 32: L09102.

(12) Hatada, K. and Kitayama, T. (2004); Nmr Spectroscopy of Polymers. Berlin, Germany: Springer Verlag.

(13) Immer, C., Starnes, J., Michalenko, M., Calle, C. and Mazumder, M. (2006) 'Electrostatic Screen for Transport of Martian and Lunar Regolith,' 37th Lunar and Planetary Science Conference, League City, Texas.

(14) Ku, C. and Lee, Y. (2007) 'Microphase Separation in Amorphous Poly(Imide Siloxane) Segmented Copolymers,' Polymer, 48: 3565-3573.

(15) Mahoney, C. M., Gardella, J. A. and Rosenfeld, J. C. (2002) 'Surface Characterization and Adhesive Properties of Poly(Imidesiloxane) Copolymers Containing Multiple Siloxane Segment Lengths,' Macromolecules, 35: 5256 - 5266. 
(16) McKay, D., Carter, J., Bole, W., Allen, C. and Allton, J. (Year) 'Jsc-1: A New Lunar Soil Simulant,' Space 94: The 4th International Conference on Engineering, Construction, and Operations in Space,

(17) Mullins, M., Micheals, L., Menon, V., Locke, B. and Ranade, M. (1992) 'Effect of Geometry on Particle Adhesion,' Aerosol Sci. Technol., 17: 105 - 118.

(18) Nishino, T., Meguro, M., Nakamae, K., Matsushita, M. and Ueda, Y. (1999) 'The Lowest Surface Free Energy Based on -Cf3 Alignment,' Langmuir, 15: 4321-4323.

(19) Park, H. B., Han, D. W. and Lee, Y. M. (2003) 'Effect of a Uv/Ozone Treatment on Siloxane-Containing Copolyimides: Surface Modification and Gas Transport Characteristics,' Chem. Mater., 15: 2346 - 2353.

(20) Patel, N., Dwight, D., Hedrick, J., Webster, D. and McGrath, J. (1988) 'Surface and Bulk Phase Separation in Block Copolymers and Their Blends. Polysulfone/Polysiloxane,' Macromolecules, 21: 2689-2696.

(21) Samseth, J., Mortensen, K., Burns, J. L. and Spontak, R. J. (1992) 'Effect of Molecular Architecture on Microstructural Characteristics in Some Polysiloxaneimide Multiblock Copolymers,' J. Appl. Polym. Sci., 44: 1245-1256.

(22) Sternovsky, Z., Sickafoose, A. A., Colwell, J. E., Robertson, S. and Horanyi, M. (2002) 'Contact Charging of Lunar and Martian Dust Simulants,' J. Geophys. Res., 107: 15-11 - 15-18.

(23) Stubbs, T., Vondrak, R. and Farrell, W. (2006) 'A Dynamic Fountain Model for Lunar Dust,' Adv. Space Res., 37: 59 - 66.

(24) Sun, Z., Dong, L., Zhuang, Y., Cao, L., Ding, M. and Feng, Z. (1992) 'Beta Relaxation in Polyimides,' Polymer, 33: 4728-4731.

(25) Taylor, L. A. and Meek, T. T. (2005) 'Microwave Sintering of Lunar Soil: Properties, Theory, and Practice,' J. Aerospace Eng., 18: 188 - 196.

(26) Taylor, L. A., Schmitt, H. H., Carrier, W. D. and Nakagawa, M. (2005) 'The Lunar Dust Problem: From Liability to Asset,' 1st Space Exploration Conference: Continuing the Voyage of Discovery, Orlando, Florida.

(27) Tiwari, A., Gupta, M. and Nema, S. (2004) 'Effect of Oxygen Plasma Asher on Poly(Methylphenylsiloxane)-Polyimide Blends,' Journal of Materials Science, 39: 1695 - 1701.

(28) Winkleman, A., Gotesmann, G., Yoffe, A. and Naaman, R. (2008) 'Immobilizing a Drop of Water: Fabricating Highly Hydrophobic Surfaces That Pin Water,' Nanoletters, 8: 1241 1245 .

(29) Wohl, C. J., Atkins, B. M. and Connell, J. W. (2011) 'Method and Apparatus for the Quantification of Particulate Adhesion Forces on Various Substrates,' National Aeronautics and Space Administration, TM-2011-217048.

(30) Wohl, C. J., Belcher, M. A., Chen, L. and Connell, J. W. (2010a) 'Laser Ablative Patterning of Copoly(Imide Siloxane)S Generating Superhydrophobic Surfaces,' Langmuir, 26: 11469-11478.

(31) Wohl, C. J., Belcher, M. A., Hopkins, J. W. and Connell, J. W. (2010b) 'Modification of Surface Energy Via Direct Laser Ablation Patterning,' US Patent Application 201012894279. 